\title{
Obituary (Professor T.C. Helvey)
}

One of the great pioneers of the interdisciplinary science of cybernetics, Professor Tibor Charles Helvey, died on 18 August, 1991, in Florida (USA), at the age of 88, a great loss to science.

Professor Helvey was educated in Hungary and Germany. After the Second World War he moved to the USA, where he was very active in academe and associated institutions; his major posts were an associate professorship in cybernetics at the University of South Florida (Tampa) and a senior professorship at the University of Tennessee Space Institute at Tullahoma; indeed, he was the first to hold such a prestigious and unique post in the USA. In addition, he has been a Visiting Professor at universities in Canada, Colombia and Peru. His research output was prodigious: 45 papers in professional journals, 34 research reports, 16 theoretical and design topics, 21 papers sponsored by grants, as well as 122 lectures and 31 papers delivered at scientific conferences in various countries. His contributions covered cybernetics, management, space technology, education, artificial intelligence, manmachine interaction, engineering and other fields.

In recognition of his valuable services, Professor Helvey received a number of Honoris Causa degrees from several universities, the Founder's Award Medal of the American Institute of Aeronautics, the Lady Davis Honorary Research Fellowship (Montreal, Canada), as well as membership of a number of scientific societies. Of a special note was the award of the Norbert Wiener Gold Memorial Medal of the World Organisation of Systems and Cybernetics. He has also acted as assistant editor of Kybernetes, and as a member of the International Journal of Biomedical Computing, Acta Symbolica, and the Journal of the ASC. The world of science has lost in his death a valuable contributor to its progress. On a personal level I have lost a great friend and dear colleague. 